\title{
The Subway Ticket System's Design and Research Based on
}

\section{Internet}

\section{Peng-yuan SUN}

\author{
School of Transfer \& Transportation, Beijing JiaotongUniversity, Beijing, China
}

Keywords: Internet, Intelligent city, Network of subway transportation, Transfer station, Transportation efficiency

\begin{abstract}
With the new technology development of Internet \& mobile payment and intelligent cities construction deep going, the city's network subway transportation system is occurring a great renovation. Directing at the passengers' transfer needs, the paper does investigation, summarizes its basic characteristic, researches and analyses the present tickets serviced system. Combining with actual running condition, aim to the condition between the passenger's transfer needs and practical services' mismatching; it develops automatic tickets service system which based on Internet. Theoretical analysis shows that the new system could save passengers' transfer time a lot, improve efficiency of the traveler. This research has significant theory and reality meaning.
\end{abstract}

\section{Introduction}

With the rapid development of economy and people's life level, people's going out efficiency has increased. Pace of life speeds up. As a result, the internet for city's transportation appears heavy barrage. The ticket's service now is mainly artificial ticket and auto-ticket-selling. Although the "city card" and "subway ticket card" had been owned by most citizens, it couldn't satisfy the people's need to buy tickets with cards. Because of there is higher and intensive human traffic rate on weekends and holidays, there are long time to line up for tickets and mechanical stoppage occurs for auto -ticket-selling. All the above affect the passengers' trip speed and efficiency.

Since the development of Internet \& mobile payment, and their advantages of safety, shortcut, high efficiency, more and more people are prone to practice the system. Nowadays, cloud-ticket service system had been practiced in first-tier-cities of China. The practice has proved that the system has many advantages, such as simplify buy-ticket process, reduce loose-change pay, and increase the efficiency of buying and boarding. These factors satisfy the passengers needs mostly and becomes growing trend in the near future. The system will take one of the most important constituent part of the intelligent transportation.

Towards the passengers 'questions and needs when they transfer from train to subway, according to Internet's high efficiency advantage, the paper researches and develops network auto-ticket- selling system. The system runs process: offer the order message by passenger, deal with the message by back-stage, return the message(bind to ID or select formation QR code) to passenger. It's the whole process of ticket order. The theoretical analysis shows that the system could save travelers' going out time 
effectively, improve trip ratio. It's convenient to peoples' trip immensely. The research possesses theoretical value and practical significance.

\section{The Status Quo and Analysis of Subway Network Ticketing System.}

The present city subway traffic network ticketing system is a combination of manual work and self-service one, which exists many problems. For example, with the increase of passenger flow, deficiency of ticket windows and vending machines, a lot of problems have appeared. It wastes too much time for people to queue up for tickets, which intensifies the labor of the staff, making the passageway blocked seriously. Based on the problems listed above, this thesis has carried out the following surveys and analytical researches.

\section{The Analysis of Manual Ticketing Conditions}

After the survey of the manual ticketing conditions, people can get the following results which are shown in Table. 1

Table 1.Survey results of the problems encountered in manual ticketing process

\begin{tabular}{|c|c|c|}
\hline Items & Subtotal & Proportions \\
\hline unclear about the destination station & 50 & $\square$ \\
\hline $\begin{array}{l}\text { failure in getting changes from ticket } \\
\text { windows during peak times }\end{array}$ & 38 & $23.75 \%$ \\
\hline difficult language communication & 12 & $7.5 \%$ \\
\hline $\begin{array}{l}\text { staff temporary leave or their rudeness } \\
\text { attitudes }\end{array}$ & 32 & E \\
\hline too long ticket window queue & 134 & $83.75 \%$ \\
\hline others & 1 & $0.63 \%$ \\
\hline effective filling in & 160 & \\
\hline
\end{tabular}

From the above survey, it is obvious that the main problem of manual ticketing system lies in the large amount of passenger flow and over concentration of peak periods. It causes the defects of long queues and too much waiting time, which makes the subway station congested. At the same time, the ticket window will have difficulty in giving changes in rush hours. The passengers could not estimate the ticketing conditions of destination stations. These above factors will bring a lot of inconvenience to passengers.

\section{The Analysis of Self-service Ticketing Conditions}

As another main ticketing system, self-service also faces many problems. The results of survey are shown in Table 2.

From the survey results in Table 2, it can be seen that the most prominent problem of the self-service ticketing window encountered is the lack of suitable changes, followed by equipment failure and unclear about transfer line. For long distance passengers, these factors will bring a lot of inconvenience. 
Table 2 Survey results of the problems encountered in self-service ticketing process

\begin{tabular}{|l|c|l|}
\hline \multicolumn{1}{|c|}{ Items } & Subtotal & $28.53 \%$ \\
\hline unclear about the destination station & 101 & Proportions \\
\hline unclear about the transfer line & 124 & 35.03\% \\
\hline complexity of screen operational process & 64 & 18.08\% \\
\hline without suitable changes & 241 & $68.08 \%$ \\
\hline machine failure, suspended service & 132 & $37.29 \%$ \\
\hline others & 12 & $3.39 \%$ \\
\hline effective filling in & 354 & \\
\hline
\end{tabular}

\section{A Comparative Study of Different Ways of Selling Tickets}

Through the analysis of the advantages and disadvantages of the subway ticketing systems, including the most widely used ones and internet plus ticketing methods, people can obtain the following results as shown in Table 3.

Table 3.A Comparison of using different ticketing methods

\begin{tabular}{|c|l|l|}
\hline \multicolumn{1}{|c|}{$\begin{array}{c}\text { Purchasing } \\
\text { ways }\end{array}$} & \multicolumn{1}{|c|}{ Advantages } & \multicolumn{1}{c|}{ Disadvantages } \\
\hline City cards & $\begin{array}{l}\text { no need to queue up } \\
\text { \& quick riding }\end{array}$ & $\begin{array}{l}\text { inconvenient for recharging \& difficult to } \\
\text { promote in all fields }\end{array}$ \\
\hline One way tickets & $\begin{array}{l}\text { suitable for individual } \\
\text { passengers\& no deposit }\end{array}$ & $\begin{array}{l}\text { low speed in purchasing \& shortage of coins } \\
\text { for operating parties \& high maintenance cost }\end{array}$ \\
\hline $\begin{array}{l}\text { Manual } \\
\text { ticketing }\end{array}$ & $\begin{array}{l}\text { Goodservice experience for } \\
\text { passengers \& slightly faster } \\
\text { purchasing speed }\end{array}$ & $\begin{array}{l}\text { causing staff costs \&great labor intensities } \\
\text { \& prone to errors }\end{array}$ \\
\hline Self-service & DIYconvenient\& quick & defects in giving changes \\
\hline Cloud ticketing & online payment & $\begin{array}{l}\text { needing to guarantee the smooth flow of } \\
\text { network communications }\end{array}$ \\
\hline
\end{tabular}

From Table 3, it can be seen that for subway passengers transferred from trains, there are three available ways to get tickets: manual, self-service and cloud purchasing. Cloud purchasing, i.e. buying, tickets online has the speed advantages in paying and printing, which can greatly facilitate travelers, improving travel efficiency and quality. Therefore, the internet plus ticketing method, is not only more suitable to meet the demands of transfer passengers, but also will become the future ticketing way.

\section{Data Acquisition and Analysis of Subway Transfer Demand}

The basis of getting the demand analysis of subway transfer passengers is the acquisition of passenger data information. The acquisition scheme is as follows:

\section{Acquisition Mode}

The questionnaire is an effective way to analyze passenger demands. In order to analyzing ticket waiting time for subway transfer passengers, this study used an online questionnaire, surveyed from different aspects : genders, ages, travel frequencies, transfer conditions, time-consuming in transferring, acceptance level of on-line ticketing, the choices of get-in modes, etc. 


\section{Results Analysis}

This data collection issued 500 questionnaires in total, of which 413 were valid questionnaires. The statistical results are as follows:

Passengers' ages and Travel Frequencies. The statistical results of the ages of passengers' and their annual travel frequencies are shown in Table 4 and Table 5.

Table 4.survey results of passengers'ages

\begin{tabular}{|c|c|c|}
\hline Items & Subtotal & Proportions \\
\hline under 18 years old & 12 & $2.91 \%$ \\
\hline $18-29$ years old & 213 & $51.57 \%$ \\
\hline $30-39$ years old & 57 & $13.8 \%$ \\
\hline $40-49$ years old & 111 & $26.88 \%$ \\
\hline $50-59$ years old & 20 & $4.84 \%$ \\
\hline 60 years old and above & 0 & $0 \%$ \\
\hline effective filling in & 413 & \\
\hline
\end{tabular}

Table 5 Outcome of annual travel frequency

\begin{tabular}{|c|c|c|}
\hline option & subtotal & percentage \\
\hline Once and more & 59 & $14.29 \%$ \\
\hline Twice to three times & 137 & ए \\
\hline Four times to five times & 126 & $30.51 \%$ \\
\hline More than six times & 91 & $22.03 \%$ \\
\hline Valid applicants of this survey & 413 & \\
\hline
\end{tabular}

Given the distributive situation of the people who travel by train, this survey focuses on the people aging from 18 to 50. Based on the survey outcome in table 4 and 5, people who travel more than four times account for over $50 \%$, so it is noticeable those people travel more frequently. With the improvement of the economic level, people will travel more often than before, so the outcome of this research is quite realistic and will get good social benefit.

The Ratio of Taking Subways after Getting off a Train. Subway has become the first choice for passengers who get off a train, for it's safe and fast.

Based on table 6 , almost $60 \%$ of the interviewees of the survey often travel by subway; people who never take subway accounts for less than $10 \%$. In that, taking subways as a transfer takes quite a large percentage, it is worthy of researching.

Table 6 outcome of survey about taking subways after getting off a train

\begin{tabular}{|l|c|l|l|}
\hline option & subtotal & percentage & $57.14 \%$ \\
\hline often & 236 & & $35.84 \%$ \\
\hline occasionally & 148 & - & $7.02 \%$ \\
\hline rarely & 29 & ए \\
\hline valid applicants of this survey & 413 & & \\
\hline
\end{tabular}

Time Consumption during the Subway Transfer. In order to study the situation of time consumption during the subway transfer, the paper will divide the whole process from getting off the train to getting on a subway into four stages: getting off the train to arriving at subway station, safety examination in subway station, queuing 
in subway station and buying a subway ticket; and the time consumption of each stage can be revealed in table 7 .

Table 7.outcome of survey about time consumption during the subway transfer

\begin{tabular}{|l|c|c|c|c|c|}
\hline \multicolumn{1}{|c|}{ stages } & $0-4$ minutes & 5 -9minutes & $10-14$ minutes & $15-19$ minutes & $\begin{array}{c}\text { over } 20 \\
\text { minutes }\end{array}$ \\
\hline $\begin{array}{l}\text { off the train to } \\
\text { subway } \\
\text { station }\end{array}$ & $59(14.29 \%)$ & $147(35.59 \%)$ & $134(32.45 \%)$ & $42(10.17 \%)$ & $31(7.51 \%)$ \\
\hline $\begin{array}{l}\text { Safety } \\
\text { examination } \\
\text { in subway } \\
\text { station }\end{array}$ & $173(41.89 \%)$ & $142(34.38 \%)$ & $58(14.04 \%)$ & $23(5.57 \%)$ & $17(4.12 \%)$ \\
\hline $\begin{array}{l}\text { queuing in } \\
\text { subway } \\
\text { station }\end{array}$ & $149(36.08 \%)$ & $134(32.45 \%)$ & $83(20.1 \%)$ & $25(6.05 \%)$ & $22(5.33 \%)$ \\
\hline $\begin{array}{l}\text { buying } \\
\text { subway ticket }\end{array}$ & $292(70.7 \%)$ & $85(20.58 \%)$ & $28(6.78 \%)$ & $6(1.45 \%)$ & $2(0.48 \%)$ \\
\hline
\end{tabular}

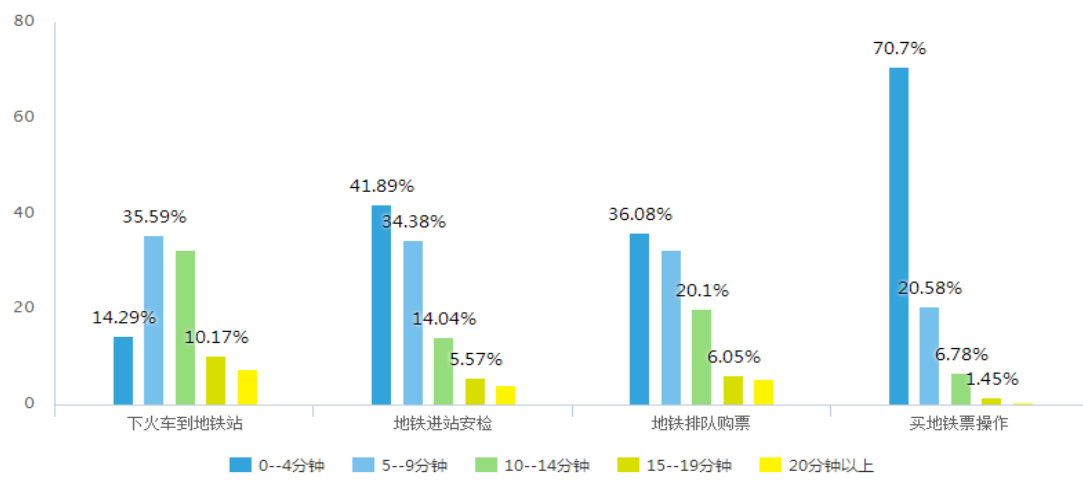

Fig. 1.Outcome of time consumption during transfer

Based on picture 1, it can be calculated the average time consumption of passengers in each transfer stage. With the weighted mean algorithm (the average of over 20 minutes is approximate to 22 minutes), and the respective time consumption of the four transfer stages is: 10.1 minutes, 6.8 minutes, 7.6 minutes and 4 minutes. From the standpoint of the passengers, it costs 7.6 minutes to queue in the subway station, 4 minutes to buy tickets there, so the total time consumption is 11.6 minutes. Accordingly, discussing about how to improve the travel efficiency is feasibly meaningful.

Survey about the Acceptance of Online Payment. The survey about the acceptance of online payment is the premise of realizing buying tickets online. The outcome of the acceptance of online payment is illustrated in table 8 .

Table 8.outcome of acceptance of online payment

\begin{tabular}{|c|c|c|}
\hline Way to pay & subtotal & percentage \\
\hline Self-service ticket machine & 253 & $61.26 \%$ \\
\hline Manual ticket window & 59 & $14.29 \%$ \\
\hline Both of the above two & 101 & $24.46 \%$ \\
\hline Valid applicants of this survey & 413 & \\
\hline
\end{tabular}


According to the outcome of the survey, we can know that people are quite familiar with the online payment procedure with the advancement of society. So it is absolutely feasible to apply online payment and online booking to subway ticket vending, which will save much time for passengers and brings a lot of convenience.

Survey about Passengers' Welcome Degree. The outcome of passengers' welcome degree towards earlier preparation of a ticket to their destination and no need to queue is illustrated in table 9.

Table 9 Outcome of survey about passengers' preference

\begin{tabular}{|c|c|c|}
\hline Welcome degree & Subtotal & percentage \\
\hline Very willing & 262 & $63.44 \%$ \\
\hline Willing & 103 & $24.94 \%$ \\
\hline Ok & 37 & $8.96 \%$ \\
\hline Not willing & 11 & $2.66 \%$ \\
\hline Valid applicants of this survey & 413 & \\
\hline
\end{tabular}

Based on the outcome of the survey in table 9, we can know that passengers are very willing to accept this subway transfer after getting off a train with continuity, higher service quality and time saving.

Survey about Passengers' Preference. As for passengers' preference, there is a survey from two aspects in this paper: 1. preference about how to enter subway station, which is shown in table 10;2. preference about how to pay for subway tickets, which is revealed in table 11

Table 10 outcome of preference about how to enter subway station

\begin{tabular}{|c|c|c|}
\hline Ways to enter subway station & subtotal & percentage \\
\hline $\begin{array}{l}\text { Now available(self-service ticket } \\
\text { machine and manual ticket window) }\end{array}$ & 70 & $16.95 \%$ \\
\hline Picking up ticket when get on a train & 59 & $14.29 \%$ \\
\hline Enter via scanning QR code & 127 & $30.75 \%$ \\
\hline Enter via scanning ID card & 150 & $36.32 \%$ \\
\hline Other ways you prefer(to fill in) & 7 & $1.69 \%$ \\
\hline Valid applicants of this survey & 413 & \\
\hline
\end{tabular}

Table 11 outcome of preference about how to pay

\begin{tabular}{|c|c|c|}
\hline Ways to pay & subtotal & percentage \\
\hline Pay online via APP & 302 & $73.12 \%$ \\
\hline Pay when getting tickets on train & 98 & $23.73 \%$ \\
\hline Others(to fill in) & 13 & $3.15 \%$ \\
\hline Valid applicants of this survey & 413 & \\
\hline
\end{tabular}

Bases on the outcomes of surveys from above two aspects, it is noticeable that the outcomes live up to our expectations. According to the first aspect, we can know that $36 \%$ of the interviewees prefer to enter via scanning ID card, and $31 \%$ of the interviewees prefer to enter via scanning QR code, namely, over $60 \%$ of passengers prefer to enter subway station via scanning ID card or QR code. This outcome directs clearly for this subject system. In the meantime, some interviewees choose the others option. The outcomes show that passengers prefer no ticket or through ticket of train 
and subway. As for ways to pay, the majority (73.12\%) of passengers prefer to pay online via APP, which indicates that we should further perfect APP.

\section{Shortcomings of Data Collecting and Measures}

1. This survey's distribution is imbalanced and most of the interviewees are from 18 years old to 29 years old. To deal with the influence of the age group, we can analyze and research by cross connection.

2. This survey is conducted merely on Internet, so not all kinds of groups are involved, so more types of survey (like field survey) will be supplemented in the future.

This paper makes a survey from two aspects about the real needs of passengers and the welcome degree towards buying tickets online. According to the analytic outcomes above, we can draw a conclusion: there is a great waste of time during the passengers' transfer from getting off a train to taking a subway.

\section{Cloud Ticketing System Design}

With the rapid development of economy, intelligent terminal has been popular in people's daily life. Designing a App ticket system is to solve a serious problem that the passengers transfer from train to subway in the low efficiency and time-consumption. This scheme is based on Android system, which is written and designed by Studio Android. App development adds a GAO De map and Android SDK, and other map development interfaces are called, to achieve the function of the path search and path planning.

\section{Main Functional Area}

App's first interface is the main functional area. By clicking the subway-ticket-reservation button, you can enter the process of booking the subway ticket, in which the settings and personal center is available by clicking "hamburger menu" on the upper right corner. In this interface, the use of button1.set On Click Listener achieves the corresponding functions, which the buttons are related to and the use of intent starts the subway- ticket-reservation interface.

The second interface of App is that user input related information. In this interface, passengers are required to enter the date, train number, departure station and destination. Information of the date, train number, station is used to identify the passengers by corresponding train tickets and subway tickets; destination information is used to book subway tickets. At the same time, passengers can enter the subway station by choosing ID card or generating two-dimensional code.

In the second interface, using (Edit Text) find View ById) method, the information of passengers input is stored as a string of character, and then use the Bundle as a container, by calling Bundle (put String) storing strings to Bundle, and then the method of Intent put Extras (Bundle) stores Bundle into intent and then passed it to the other following Activity. Therefore, transferring passengers' data is achieved.

There is a confirm button on the right side of the information-inputting box. Click on the button, after the passenger complete information. The button will automatically jump to Geocode Activity, that is, the activities of geo coding. Geographical coding is also known as the address matching, that is, a conversed process from the known address to the corresponding latitude and longitude. Here Gao De large national name database is called to converse by Geocode Query which set query parameters, and Geocode Search (get From Location Name Asyn) is called to request, and results are 
analyzed through the callback interface of on Geocode Searched.

\section{Confirmation of Subway Ticket Information}

In the last step, the passengers will come to this final confirmation interface, after clicking on the "confirmation" button. The interface shows the information of the subway ticket that passengers have booked including, fares, fees and total price. Below the starting and ending point is the "view-the-circuit-diagram" button, which will automatically jump to detailed interface with the route by clicking. Click on "immediately pay" to enter the payment interface. In this interface, we use get Intent() method to receive previous geographic information and use Text View. Set Text () method to display address in the interface so that passengers confirm the starting and ending points.

\section{Path Planning}

According to the traffic survey, passenger are most concerned about the travel time in the process of transportation, the passengers choosing a path is depended directly on travel time, but in a certain range, the passengers will choose the optimal transferring path, therefore, path planning is added in the system. In the previous step, the passengers clicking on "click to view the circuit diagram" will jump to the path-planning interface. This interface will plan the path based on the latitude and longitude which address is converted into. First, use the Map View as a map container, load the map, use set from and to Marker () method to display icon of starting and ending point. After passengers click on the button, the search Route Result () method is used to search path planning, mBus Route Result stored search results, on Bus Route Searched (Result) is used to analyze the result., and finally get the distance, fares and other information, filtering invalid information and simplifying the process. When the result does not exist, it will show that I am sorry, there is no relevant data!"

\section{Analysis on Practicability of Cloud Ticketing System}

Internet-based scheme for the automatic ticket booking system can save a lot of unnecessary links in the process of booking for the passenger, such as the long queues, not knowing how to choose the transferring route and so on, thus passengers will save a lot of time in the process of booking and efficiency and quality of travel is improved. At the same time, entering station by binding ID or generating two-dimensional code can save the sectors of hand-out and recovery a metro card, thereby the cost of subway operation is saved and the results can yield good social benefits.

\section{Conclusion}

Transferring from train to subway, due to large flows of traffic and time concentration, often causes queue, traffic jam in the entrance of the station, resulting in long-time waiting. In terms of low efficiency of subway, this paper finds out the causes of wasting time in the process of transfer on the basis of lots of investigation, through in-depth analysis and study, puts forward payment scheme based on new technology through Internet plus online booking system, mobile payment. Many problems can be solved in the transfer process, so as to save a large number of transfer times. At the same time, passengers can choose to bind ID or generate two-dimensional code into the subway station, thus effectively improve the traffic efficiency of subway station. Through the effective combination of Internet and subway ticketing, passengers can 
not only simplify the purchase process, reduce the usage rate of pocket money, improve ticket-booking speed, alleviate the pressure but also reduce the cost of equipment maintenance, enhance the service quality of the subway operation. Due to the limited conditions, the data acquisition of this study is rather less, so the next step is to expand the number of surveys, to lay the foundation for further system optimization.

\section{References}

[1] Jian-fengZou, Shan-feng Zhou. Speech of Exploit Case for Company. People's Telecommunications Press, $(2004,6)$

[2] Hong caiTao, Database Principle \& Design. THU Press. (2004)

[3] XueyunJin, Asp.net. Briefer Course. THU Press $(2005,5)$

[4] Zhen qiu Fang, Train's Self-service Ticket System Design \&Development. Research Institute of Railway Science. $(2003,6)$

[5] Jun Huang, The Database Safety Communication System for Railway Booking Network. CnengDu University of Science \&Engineering. (2002,5) 